\title{
Sinus of Valsalva aneurysms, tunnels, fistulas, and blue moons
}

\author{
Johann Brink, MD, ${ }^{a}$ and Yves d'Udekem, $\mathrm{MD}, \mathrm{PhD}^{\mathrm{a}, \mathrm{b}, \mathrm{c}}$
}

\footnotetext{
From the ${ }^{\mathrm{a} D e p a r t m e n t}$ of Cardiac Surgery, Royal Children's Hospital; ${ }^{\mathrm{b}}$ Murdoch Children's Research Institute, Heart Research Group; and ${ }^{\mathrm{c}}$ Department of Paediatrics, Faculty of Medicine, The University of Melbourne, Melbourne, Australia.

Disclosures: Dr d'Udekem is a consultant for MSD and Actelion. The Victorian Government's Operational Infrastructure Support Program supported this research project. Dr d'Udekem is Nation Health and Medical Research Council Clinician Practitioner Fellow (1082186). Dr Brink has nothing to disclose with regard to commercial support.

Received for publication Aug 22, 2017; accepted for publication Aug 26, 2017; available ahead of print Sept 23 , 2017.

Address for reprints: Yves d'Udekem, MD, PhD, Department of Cardiac Surgery, The Royal Children's Hospital, Flemington Rd, Parkville, Victoria 3052, Australia (E-mail: yves.dudekem@rch.org.au).

J Thorac Cardiovasc Surg 2018; 155:e55

$0022-5223 / \$ 36.00$

Copyright (C) 2017 by The American Association for Thoracic Surgery

http://dx.doi.org/10.1016/j.jtcvs.2017.08.086
}

Aorta-right atrial tunnels are rare and the topic of a few sporadic reports. They were first described by Coto and colleagues in 1980. ${ }^{1}$ Morphologically, these tunnels consist of a tubular connection originating from any of the sinuses of Valsalva in the aortic root or even above the sinotubular junction terminating in the right atrium. ${ }^{2}$ The embryologic development or cause is still unclear, but congenital elastin deficiency may be a contributing factor leading to propagation of an aneurysm or tunnel under high aortic pressure. The pathophysiology of aorta-right atrial tunnels is similar to left-toright shunts at the atrial level and the lesion may be discovered coincidentally or present with heart failure depending on the amount of shunting. In the current issue, Dellis and colleagues $^{3}$ describe with clear illustrations a large fistula originating centrally from an aneurysmal left coronary sinus and draining into the right atrium. The lesion was successfully managed surgically by simple direct closure at both ends.

Two-dimensional echocardiography can accurately demonstrate these lesions in detail and combined with computed tomography and coronary angiography, differentiation between coronary artery fistulas and ruptured sinus of Valsalva aneurysms may be achieved. Whilst the authors did not perform a coronary angiogram, Dellis and colleagues ${ }^{3}$ clearly identified at surgery that coronary arteries were not involved, thus eliminating the possibility of a coronary artery fistula. This lesion may be the result of a ruptured sinus with propagation into the right atrium. Differentiation of tunnels from a ruptured sinus of Valsalva aneurysm may not be so simple. Some have suggested that tunnels only arise above the coronary ostia and even the sinotubular junction. ${ }^{4}$

The authors correctly justified the indications for surgery in a symptomatic patient with a large aneurysmal fistula followed by a successful simple surgical repair. But what about an aorta-right atrial tunnel in an asymptomatic patient? Lee and colleagues ${ }^{5}$ described such a case in their article, "Is surgical correction mandatory?" They performed shunt quantification with magnetic resonance and

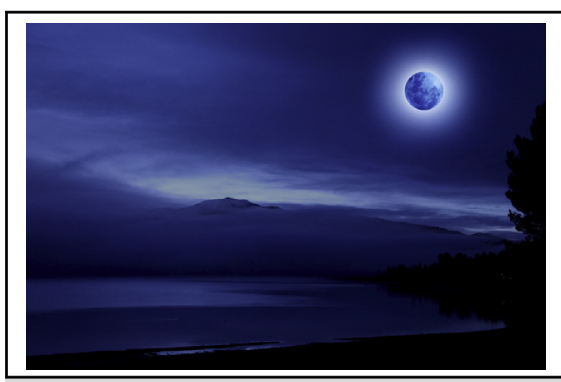

Rare beauty of a blue moon at Lake Tekapo, New Zealand.
Central Message
Aorta-right atrial tunnels are rare anomalies
and can be difficult to distinguish from Valsalva
aneurysms and coronary artery fistulas; howev-
er, this lesion does not pose much of a surgical
challenge.

See Article page e51. claim that medical observation is justified in some cases. In these minor cases, some surgeons may favor surgical correction because the ongoing risk of infective endocarditis, rupture, and progressive aortic valve or coronary artery involvement.

Treatment options for aorta-right atrial tunnels range from transcatheter coil embolization and simple surgical ligation to more complex repairs that include coronary artery reimplantation with excellent surgical results. ${ }^{2,6,7}$ However, in most of the reported cases, the surgical strategy consisted of direct closure at the aortic end with or without closure of the right atrial end. These lesions, such as blue moons, can mesmerize us by their unusual beauty and rarity, but unlikely pose a surgical challenge.

\section{References}

1. Coto EO, Caffarena JM, Such M, Marques JL. Aorta—right atrial communication. Report of an unusual case. J Thorac Cardiovasc Surg. 1980;80:941-4.

2. Gajjar T, Voleti C, Matta R, Iyer R, Dash PK, Desai N. Aorta-right atrial tunnel: clinical presentation, diagnostic criteria, and surgical options. J Thorac Cardiovasc Surg. 2005;130:1287-92.

3. Dellis SL, Pennel T, Said-Hartley Q, Zilla P. Sinus of Valsalva-right atrial tunne causing heart failure in a 38-year-old. J Thorac Cardiovasc Surg. 2018;155:e51-3.

4. Ho SY, Muriago M, Cook AC, Thiene G, Anderson RH. Surgical anatomy of aorto-left ventricular tunnel. Ann Thorac Surg. 1998;65:509-14.

5. Lee S, Kim SW, Im SI, Yong HS, Choi CU, Lim HE, et al. Aorta-right atrial tunnel: is surgical correction mandatory? Circulation. 2016;133:e454-7.

6. Türkay C, Gölbaşi İ, Belgi A, Tepe S, Bayezid Ö. Aorta-right atrial tunnel J Thorac Cardiovasc Surg. 2003;125:1058-60.

7. Yim D, Yong MS, d'Udekem Y, Brizard CP, Konstantinov I E. Early surgical repai of the coronary artery fistulae in children: 30 years of experience. Ann Thorac Surg. 2015;100:188-94. 